\title{
Early appearance of 2,3-butanediol in acute myocardial infarction. A new marker for ischaemia?
}

\author{
K. R. HeER, H. Stalder AND H. ThOELEN \\ Departement Forschung Kantonsspital Basel, and Medizinische Abteilung Kantonsspital Liestal, Switzerland
}

KEY WORDS: Acute myocardial infarction, 2,3-butanediol, ischaemia.

In 28 patients with acute myocardial infarction, the release pattern of 2,3-butanediol (BD), a product of intermediary metabolism, and creatine kinase activity $(C K)$ in blood were compared. Whereas $C K$ at entry was low in all patients, the BD level was elevated in $18(64 \%)$. However, BD returned to normal levels during the next $24 \mathrm{~h}$ whereas $C K$ increased. The $B D$ level at entry did not allow differentiation between patients with transmural or non-transmural infarction; it was independent of clinical findings and biochemical parameters. We suggest that, in patients with acute myocardial infarction, elevated levels of BD originates from myocardial metabolism. Whether it reflects ongoing ischaemia or reperfusion of the infarcted area remains unresolved.

\section{Introduction}

In the early phase of myocardial infarction, no biochemical parameter for myocardial ischaemia is known in the peripheral venous blood. Elevation of plasma creatine kinase occurs late and indicates myocardial injury or cell necrosis. A biochemical parameter for ischaemia however could be important for stratifying patients with acute chest pain.

2,3-butanediol (BD) is a product of intermediary metabolism; its precursors are pyruvate, acetaldehyde and acetoin ${ }^{[1,2]}$. In his studies of the enzymatic synthesis and breakdown of acetoin in the animal organism, Järnefelt has shown that, under anaerobic conditions, the formation of BD is accelerated ${ }^{[3]}$. In a preliminary study we found elevated levels of BD in some patients with acute myocardial infarction.

We report a prospective study of 28 patients with acute myocardial infarction. In addition to conventional clinical, electrocardiographic and enzymatic techniques we performed frequent serial determinations of BD to assess its release pattern.

\section{Patients and methods}

Of 121 consecutive patients with chest pain who were admitted to the coronary care unit, 21 men and 7 women (age 42 to 84 years) were included in the prospective study. All 28 patients had typical chest Submitled for publication on 1 November 1988, and in revised form 24 November 1989.

Address for correspondence K. R. Heer, Kasernenstrasse 22A, 4410 Luestal, Switzerland. pain of at least 30 min duration, which had occurred within the preceding $6 \mathrm{~h}$. Serial electrocardiograms showed in all cases either $Q$ wave evolution or typical S-T wave changes. Increase of CK activity during the first day was noted in 22 patients. As a reference group, we determined $\mathrm{BD}$ in 23 patients with stable angina pectoris (aged 29-78 years).

For the analysis of 2,3-butanediol, $10 \mathrm{ml}$ samples of venous blood were taken at $2,4,6,9,12$ and $24 \mathrm{~h}$ after the onset of pain. The blood was deproteinized immediately with sulphuric and tungstic acid. The supernatant was frozen at $-20^{\circ} \mathrm{C}$ and stored. The samples were analysed according to the method described by Happold and Spencer ${ }^{[4]}$ and Westerfeld ${ }^{[5]}$. 2,3-butanediol in the supernatant was oxidized to diacetyl with bromide and ferrichloride; diacetyl was reacted with 2,4-dinitrophenylhydrazine. The precipitated hydrazone was filtered and determined colorimetrically. The relative coefficient of variation was less than $5 \%$; normal levels are below $0.029 \mathrm{mmol} \mathrm{I}^{-1}$. The results were obtainable within $8 \mathrm{~h}$. CK activity was measured with a commercially available diagnostic kit (Merck); normal values are below $80 \mathrm{U}^{-1}$.

Results are expressed as the mean \pm SD (SEM where noted). Unpaired Student's $t$-test was used for statistical analysis.

\section{Results}

In a group of 28 patients with acute myocardial infarction, BD showed a release pattern contrasting to the rise of CK during the first $24 \mathrm{~h}$ (Fig. 1). 
At entry, 18 of 28 patients had elevated levels of BD, $0.087 \pm 0.036 \mathrm{mmol} \mathrm{l}^{-1}$ (range 0.055 $\left.0.188 \mathrm{mmol}^{-1}\right)$, which decreased to normal levels within $24 \mathrm{~h}, 0.025 \pm 0.015 \mathrm{mmol}^{-1}$. In 10 other patients, $\mathrm{BD}$ was found to be normal at entry, $0.012 \pm 0.006 \mathrm{mmol} \mathrm{I}^{-1}$ (range 0.006 $0.026 \mathrm{mmol}^{-1}$ ); in eight it remained normal during the $24 \mathrm{~h}$, whereas in two minor changes were noted. No significant difference in history (unstable angina pectoris and old myocardial infarction), clinical presentation at entry (Killip), duration of chest pain or need for antiarrhythmic therapy was found between patients with high or low levels of $B D$. The release of $\mathrm{BD}$ was independent of time of admission and history of alcohol consumption. In 23 patients with stable angina pectoris the mean value of BD was $0.015 \pm 0.005 \mathrm{mmol} \mathrm{l}^{-1}$ (range 0.008 $0.029 \mathrm{mmol} \mathrm{l}^{-1}$ ).

Twenty-one patients showed a typical rise in CK during the first $24 \mathrm{~h}$; CK was higher in transmural than in non-transmural infarction. No or little rise in $\mathrm{CK}$ was found in four patients with low $\mathrm{BD}$ and in three patients with high BD at entry; they all had non-transmural infarction. There was no direct relationship between BD level and CK activity; however patients with high BD at entry showed a non-significantly higher level of $\mathrm{CK} 9 \mathrm{~h}$ after the onset of chest pain. In addition, patients with transmural infarction had a significantly higher BD level at $12 \mathrm{~h}$ than patients with non-transmural infarction $(P<0.02)$.

Two patients died; both were in cardiogenic shock on admission and both had transmural infarction. Their BD levels were $0.017 \mathrm{mmol}^{-1}$ and $0.049 \mathrm{mmol} \mathrm{I}^{-1}$.

\section{Discussion}

BD at entry in 28 patients with acute myocardial infarction was found to be significantly different from $B D$ in a group of 23 patients with stable angina pectoris $(P<0.001)$. However, a difference in release pattern was noted within the group of acute myocardial infarction patients. In 18 of 28 patients $(64 \%)$, BD was elevated at entry and returned to normal within $24 \mathrm{~h}$; in 10 patients $(36 \%)$ BD remained normal during the study period. This different pattern was related neither to the localization or extent of the infarction nor to clinical parameters. However at $12 \mathrm{~h}$ after the onset of pain, $\mathrm{BD}$ was significantly higher in patients with transmural infarction (Fig. 1). We suggest that BD is a product of ischaemic myocardial metabolism which
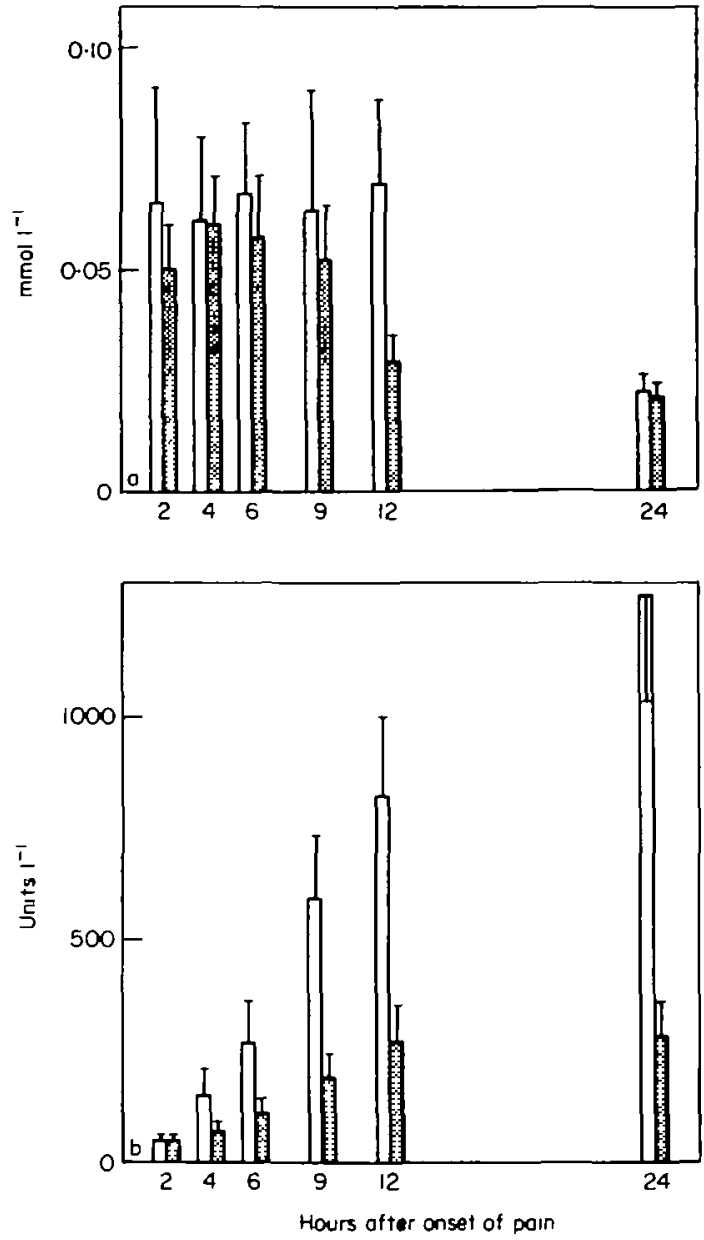

Figure 1 2,3-butanediol (a) and creatine kinase (b) during the first $24 \mathrm{~h}$ in 28 patients with acute myocardial infarction (mean $\pm S E M$ ). Open area: transmural infarction; dashed area: non-transmural infarction.

is released early into the peripheral circulation, unlike CK, which is found in blood only after some hours. This is supported by the study of Järnefelt who showed that $\mathrm{BD}$ is produced in heart muscle and that production is increased under anaerobic conditions $^{[3]}$. We suppose that BD crosses the cellular membrane early in the course of ischaemia, as does lactate which can be found in the coronary sinus but not in the peripheral blood ${ }^{[6]}$. Both metabolites have a low molecular weight. However, it still remains unresolved whether elevated BD at entry indicates ongoing ischaemia or washout of ischaemic metabolites by natural reperfusion of the infarcted area. As evolution of a myocardial infarction is considered to be a dynamic process ${ }^{\pi}$, the 
explanation is even more difficult. The finding that in patients with transmural infarction $B D$ remains elevated during the first $12 \mathrm{~h}$ in comparison to non-transmural infarction could however be due to dynamic alteration of myocardial metabolism and perfusion. In patients with non-transmural infarction this dynamic process would be of shorter duration with earlier reperfusion; however, one can not exclude the possibility that in these patients the ischaemic area at the onset of pain is large enough to produce substantial quantity of BD. Indeed in 11 of 19 patients with non-transmural infarction, BD was high at entry, $0.083 \pm 0.021 \mathrm{mmol} \mathrm{I}^{-1}$ (range 0.056-0.114 $\mathrm{mmol} \mathrm{l}^{-1}$ ).

Different patterns of BD could also be due to different metabolism and excretion of the metabolite itself. However this seems to be less likely, although little is known about metabolism and excretion. Söling et al. concluded from their rat study that approximately $80 \%$ of infused $\mathrm{BD}$ was absorbed by the peripheral tissue within $2-4 \mathrm{~h}^{[8]}$. From their cat studies, Dawson and Hullin came to the conclusion that $\mathrm{BD}$ was rapidly metabolized as a first step (up to $90 \%$ within the first hours); the second step would be slow ${ }^{[1]}$. According to observations by Westerfeld and Berg, urinary excretion is minor ${ }^{\{9\}}$.

Elevated levels of BD are also found in patients with hepatic or uraemic coma ${ }^{[10]}$; rising blood glucose in diabetics is accompanied by a rising level of $\mathrm{BD}^{[11]}$. However no patient of our study had renal or hepatic insufficiency or a metabolic disorder. Elevated alcohol intake could be excluded from the patients' history. They also had no pulmonary embolism or perimyocarditis.

The findings of our study suggest that elevated $\mathrm{BD}$ in blood of patients with acute myocardial infarction originates from ischaemic myocardial metabolism. Whether it indicates ongoing ischaemia or reperfusion still remains unresolved. Further studies are needed to support our results and to clarify their relevance for managing patients with acute myocardial infarction. New and rapid laboratory methods are needed.

We are indebted to Miss Astrid Gysin for technical assistance and to the nursing staff of the intensive care unit for obtaining blood samples.

\section{References}

[1] Dawson J, Hullin RP. Metabolism of acetoin. Biochem 1954; 57: 177-85.

[2] Schreiber G, Kohlhaw G, Goedde HW, Holzer H. Die Biosynthese von Acetoin in Schweineherzmuskel. Biochem Zeitschrift 1963; 339: 83-93.

[3] Jarnefelt J. Studies on the enzymatic synthesis and breakdown of acetoin in the animal organism. Ann Acad Sci Fenn 1955; V: 1-78.

[4] Happold FC, Spencer CP. The bacterial formation of acetylmethylcarbinol and 2,3-butylene glycol. Biochim Biophys Acta (AMST) 1952; 8: 18-29.

[5] Westerfeld WW. Colorimetric determination of blood acetoin. J Biol Chem 1945; 161: 495-502.

[6] Opie LH, Owen P, Thomas M, Samson R. Coronary sinus lactate measurements in assessment of myocardial ischemia. Am J Cardiol 1973; 32: 295-305.

[7] Davies MJ, Thomas AC. Plaque fissuring - the cause of acute myocardial infarction, sudden ischemic death, and crescendo angina. Br Heart J 1985; 53: 363-73.

[8] Söling HD, Kohlhaw G, Schnermann J, Holzer H, Creutzfeldt W. Zur Bedeutung des Acetoins fūr die Pathogenese des Coma hepaticum. Dtsch Med Wschr 1964; 10: 457-64.

[9] Westerfeld WW, Berg RL. Observations on the metabolism of acetoin. J Biol Chem 1943; 148: 523-8.

[10] Thoelen H, Bigler F, Stauffacher W, Staub H. Zur Pathogenese des Urämiesyndromes. Brenztraubensäure, Acetoin und 2,3-Butylenglycol in Blut von Patienten mit Nieren- und Leberkrankheiten. Experientia (Basel) 1962; 18: 454-5.

[11] Stöcklin MR. Das Verhalten von Brenztraubensāure, Milchsäure, Acetaldehyd, Acetoin, 2,3-Butylenglycol und ph-Wert im Blut bei Diabetes mellitus. Dissertation. University of Basel, 1975. 